\title{
A TEORIA CRÍTICA DE GRAMSCI NAS PEDAGOGIAS ALTERNATIVAS DE EDUCAÇÃO DO CAMPO
}

\author{
THE CRITICAL THEORY OF GRAMSCI IN ALTERNATIVE \\ PEDAGOGIES OF EDUCATION IN THE RURAL AREAS \\ LA THÉORIE CRITIQUE DE GRAMSCI DANS LES PÉDAGOGIES \\ ALTERNATIVES DE L'ÉDUCATION EN MILIEU RURAL \\ LA TEORÍA CRÍTICA DE GRAMSCI EN LAS PEDAGOGÍAS \\ ALTERNATIVAS DE LA EDUCACIÓN DEL CAMPO
}

Claudemiro Godoy do Nascimento*

\section{RESUMO}

Este artigo busca refletir sobre a contribuição do pensamento de Gramsci na elaboração e aplicação das pedagogias alternativas de educação do campo, em especial, a dos Centros de Formação em Alternância, que trabalham com a Pedagogia da Alternância no Brasil. As discussōes sobre educação do campo no Brasil são bem recentes e há dez anos vêm se fortalecendo enquanto espaço de construção do conhecimento e de saberes que se confirmam a partir das próprias experiências de sujeitos coletivos que constroem espaços pedagógicos alternativos, na concepção gramsciana, contra a hegemonia estabelecida.

Palavras-chave: Educação do campo. Pedagogias alternativas. Gramsci. Teoria crítica.

* Licenciado em Filosofia pela Universidade Católica de Goiás (1999). Graduado em Teologia pelo Instituto de Teologia Santa Úrsula (2005). Mestre em Educação pela Universidade Estadual de Campinas (2005). Doutorando em Educação pela Universidade de Brasília. Professor da Universidade Federal do Tocantins (claugnas@globo.com). 


\section{INTRODUÇÃO}

A educação do campo pode ser considerada nesta primeira década do século XXI uma área de concentração científica preocupada com as demandas provenientes do universo campesino. Seu surgimento se efetiva a partir da década de 90 do século XX, quando as produções científicas sobre as experiências de educação do MST e de outros movimentos sociais do campo produzem novas formas pedagógicas de se pensar o processo de ensino-aprendizagem destinado aos trabalhadores rurais. Além disso, tornou-se um contraponto ao modelo de educação rural vigente, voltado para atender escolas rurais isoladas com pedagogias tradicionais que não respeitam o universo simbólico dos camponeses, em especial, os novos agentes sociais do campo, a saber: os assentados provenientes da luta pela terra.

Dessa forma, queremos refletir neste artigo a respeito do lugar da educação do campo na sociedade brasileira a partir da teoria crítica de Gramsci. Por meio dos movimentos sociais do campo, conseguiu-se criar alternativas de educação ao produzir experiências de pedagogias contrárias ao modelo hegemônico existente na sociedade brasileira. Evidentemente, outros autores como Paulo Freire, Moacir Gadotti, Dermerval Saviani, Florestan Fernandes, Alain Touraine e François Houtart contribuíram e contribuem para tal construção teórica de uma prática alternativa de pedagogias que constroem o que chamamos de educação do campo. No entanto, pelas pedagogias existentes, a educação do campo pensada a partir das bandeiras de luta dos próprios trabalhadores rurais não se enquadra naquelas apontadas por Saviani (2001) como tradicional, escolanovista e críticoreprodutivista. Portanto, inserem-se numa pedagogia crítica conforme destacam D’Ávila (1985) e Freitag (1980), alternativa ao modelo de educação tradicional, escolanovista e crítico-reprodutivista, e que se encontra alicerçada no pensamento crítico de Gramsci.

Esta reflexão terá três momentos que dialeticamente se interligam. No primeiro, analisar-se-á o contexto da educação do campo, suas origens, seu projeto-político pedagógico crítico e sua história, que se constrói como oposição ao modelo de educação ofertado aos trabalhadores rurais há décadas em forma de descaso. No segundo momento, compreenderse-á a análise do pensamento de Gramsci (2001), com as colaborações de Mochcovitch (1988), D’Ávila (1985), Freitag (1980) e Gohn (1999), que contribuíram para o entendimento do arcabouço teórico no qual se encontra inserido o movimento de educação do campo, que surgiu no Brasil a partir da década de 90. E, por fim, no terceiro momento se apresentará a experiência de pedagogia alternativa dos Centros Familiares de Educação por Alternância (CEFFAs), que contribuem com a formulação de uma pedagogia da alternância destinada aos trabalhadores rurais no Brasil desde 1969.

A partir desse caminho proposto, queremos problematizar o conceito de educação de campo que vem sendo considerada fonte de investigação científica em Programas de PósGraduação nas universidades brasileiras, bem como em cursos de graduação destinados a atender os povos do campo. 


\section{ANTECEDENTES HISTÓRICOS}

A educação destinada aos trabalhadores rurais sempre foi motivo de muita discussão e controvérsia. As políticas educacionais criadas pelos governos colocavam a oferta de educação de uma forma geral. Desde o Brasil Colônia, a educação foi pensada e ofertada somente aos filhos da elite, que eram instruídos para dar continuidade ao projeto de perpetuação da desigualdade social entre ricos e pobres. Os pobres, em sua grande maioria indígenas, escravos negros e camponeses, tinham a catequização dos jesuítas como consolo, já que precisavam ser instruídos na fé católica e na obediência à Coroa de Portugal. A catequização não significava letramento, alfabetização, mas o aprendizado mínimo das regras de conduta da Igreja, que serviam de legitimação para as práticas de escravidão e exploração dos portugueses. Dessa forma, conforme afirma Saviani (1997), as propostas dos jesuítas e dos portugueses se interligavam criando uma tríplice necessidade que não poderia dicotomizar-se, a saber: colonização, educação e catequese deveriam caminhar articuladas para um mesmo objetivo, que era levar a fé católica como salvação das almas e ampliar a exploração realizada pelos portugueses.

Portanto, aos trabalhadores do campo era destinada a enxada e a foice para que pudessem cumprir bem seu ofício, o que determinava a perpetuação do poder aos senhores de engenho e, posteriormente, aos coronéis das fazendas de café. De certa forma, desde 1550, quando realmente se iniciou o processo de catequização dos jesuítas, até os anos 70 e 80 do século XX, ou seja, durante mais de 400 anos de história, os camponeses foram relegados ao descaso. Enquanto na cidade os trabalhadores se organizavam na busca de seus direitos de cidadania, no campo os trabalhadores rurais continuavam sem organização e, em muitos lugares, eram expulsos de suas terras devido à ampliação do latifúndio, principalmente com o crescimento da pecuária.

Em algumas ocasiōes na história do Brasil, os camponeses foram sinônimos de resistência ao modelo imposto. São considerados os primeiros movimentos sociais do campo devido às bandeiras de luta que estavam clamando. São eles: Contestado, no Paraná e Santa Catarina, Canudos, na Bahia, o Cangaço, no Nordeste Brasileiro e, por fim, as Ligas Camponesas, que deram origem à Revolta de Trombas e Formoso em Goiás. Outros pequenos movimentos isolados aconteciam, mas sem nenhuma repercussão nacional, já que a força da oligarquia rural atrelada aos interesses do capital conseguia silenciar a voz e as manifestações dos trabalhadores rurais.

Leite (1999) consegue fazer uma abordagem das políticas educacionais urbanocêntricas que eram oferecidas às escolas rurais. $\mathrm{O}$ autor faz um balanço do Estado liberal moderno e, consequentemente, da trajetória sócio-histórica da escola rural, desde a República Velha até o ruralismo pedagógico, a escolarização rural no Estado Novo, as extensões rurais, as campanhas nacionais de alfabetização no meio rural, a educação de base, a educação rural no contexto do Estado Militar e para onde caminha a escola rural com a última LDB, Lei no 9.394/96 (BRASIL, 1996). No entanto, Leite não consegue sair 
do espírito crítico-reprodutivista, que vê a existência de um projeto liberal capitalista permeando as relações no meio rural, mas que, em nenhum momento, aponta para as alternativas existentes e concretas que foram construídas a partir dos movimentos sociais do campo, em especial com a CPT e o MST.

A Comissão Pastoral da Terra é um organismo ligado à Conferência Nacional dos Bispos do Brasil (CNBB), fundada em 1975. O surgimento da CPT se deve ao momento histórico vivido pela Igreja Católica no Brasil e na América Latina. Com a realização do Concílio Vaticano II (1962-1965), a Igreja abria-se ao mundo, principalmente na defesa dos pobres. Tratava-se da tentativa de retornar às origens do cristianismo primitivo, a Igreja dos Pobres. Com isso, na América Latina surge a Teologia da Libertação, impulsionada pelos bispos progressistas que incentivaram a formação de novos padres alimentados da esperança de que a Igreja poderia contribuir para transformar a sociedade. Da sacristia às ruas, do púlpito às manifestações por Reforma Agrária, a Igreja já não era mais a mesma, havia algo de especial, de novo, de sonhos e utopias, como costumam dizer os agentes de pastoral. Daí surgiram as CEBs (Comunidades Eclesiais de Base) e as diversas pastorais, sempre ligadas aos grupos sociais minoritários, a saber: Pastoral da Terra, do Menor, da Mulher Marginalizada, da Criança, da Juventude, dos Migrantes, entre outras tantas que se organizavam nacional ou regionalmente.

É daí que surge a CPT. A CPT, como organismo da CNBB, iniciou o trabalho pastoral em 1975, na tentativa de organizar os camponeses para lutar por Reforma Agrária. A questão era urgente, pois se tratava de tirar da miséria milhões de famílias. A prática de ocupaçóes torna-se o maior recurso pedagógico dos camponeses articulados ao redor da Cruz (símbolo do catolicismo) que os protegia. O urgente era a terra, depois viriam outras demandas, como educação, saúde, crédito rural etc. Portanto, em um primeiro momento, os camponeses foram organizados pela CPT para que depois pudessem caminhar com suas próprias pernas, como diz Dom Tomás Balduíno, fundador e Presidente da CPT. Dessa organização, por meio de ocupaçōes de terra, de assembléias, de encontros, de Seminários sobre Reforma Agrária, Conjuntura Política Internacional e Nacional, é que foram sendo formados os líderes dos camponeses que no Encontro da CPT em Cascavel fundaram o Movimento dos Trabalhadores Rurais Sem Terra - MST em 1984.

O MST constitui-se na sociedade brasileira como o maior movimento social. A aliança CPT e MST continua, mas agora se vêem os próprios trabalhadores como sujeitos de suas açôes coletivas, conseguindo caminhar com as próprias pernas. A CPT continua auxiliando até hoje os assentamentos e acampamentos, além de oferecer, todos os anos, um mapa da violência existente no campo. O MST, aos poucos, foi crescendo e alcançou prestígio, medo, por parte das elites oligárquicas, fama e reconhecimento de entidades internacionais como a Unesco.

Com as realizações de Congressos, Seminários e Encontros, o MST foi construindo outras pautas e bandeiras de luta, entre elas a educação. Dividido em setores, dentre eles 
o Setor Educação do MST, o movimento começou a realizar Seminários e Encontros para se tratar da temática de cada setor. Com a realização do I Encontro de Educadoras e Educadores do Campo (Enera), realizado em 1997, há uma década, é que surgiu a idéia dos participantes de organizar o movimento de Educação do Campo. Em 1998, organizase a I Conferência Nacional Por uma Educação Básica do Campo, que se reuniu na cidade de Luziânia de 27 a 31 de julho. A organização da I Conferência se deu a partir de uma parceria entre MST, CNBB, Unesco, Unicef e Universidade de Brasília - UnB, que foram as entidades promotoras.

Nascia assim a Educação do Campo, de certa forma como resposta à falta de políticas públicas implementadas pelo Estado e por tratar a educação do campo como educação rural com concepçōes pedagógicas provenientes do mundo urbano e sem nenhuma utilidade aos interesses dos trabalhadores rurais. Pelo contrário, a educação rural organizada pelos municípios e com políticas educacionais ligadas às Secretarias Estaduais de Educação e ao MEC era (e, ainda é) profundamente inútil frente aos problemas do homem e da mulher do campo. Em outro trabalho, afirmo os ideais da educação do campo como sendo:

A educação camponesa se constrói a partir de um movimento sócio-cultural de humanização. Centraliza-se na busca pela pedagogia do ritual, do gesto, do corpo, da representação, da comemoração e do ato de fazer memória coletiva. As pessoas, gente simples do campo, tornam-se sujeitos culturais celebrando sua memória ao resgatar a identidade por meio da educação. Assim, a educação do campo é chamada a construir matrizes humanistas para o Homem do campo tendo em vista a emancipação humana. Os projetos entre educação do campo e a educação formal e bancária do Governo são paradoxais. Na educação do campo todos são sujeitos e construtores de memória e da história, ou seja, todos são sujeitos sociais e culturais. Já na educação formal, a escolarização, apresentada como único modelo pedagógico a todos os brasileiros (as), reduz alunos (as) a: aprovados ou reprovados, novatos ou repetentes, defasados especiais ou anormais, além de criar um dualismo entre educador/educando (NASCIMENTO, 2002, p. 455).

Em 2004, dos dias 2 a 6 de agosto na cidade de Luziânia, é realizada a II Conferência Nacional de Educação do Campo, ${ }^{2}$ que clamava por Política Pública de Educação do Campo. Nessa Conferência há a adesão de outros movimentos sociais, ONGs e Centros que se unem ao Movimento de Educação do Campo, que se fortalece de 1998 a 2004. Entre eles, destaco: a Contag e os Centros Familiares de Formação por Alternância, que não participaram efetivamente da I Conferência de 1998.

A Declaração Final da II Conferência traz alguns aspectos metodológicos interessantes, a saber: apresenta inicialmente quem somos e de onde viemos e realiza uma retomada histórica da educação do campo. A seguir, a declaração apresenta o que defendem os trabalhadores do campo e qual é a sua luta.

Lutamos por um projeto de sociedade que seja justo, democrático e igualitário; que contemple um projeto de desenvolvimento sustentável do campo, que se contraponha ao latifúndio e ao 
Agronegócio. (...) Lutamos por um projeto de desenvolvimento do campo onde a educação desempenhe um papel estratégico no processo de sua construção e implementação. (Declaração Final da II Conferência de Educação do Campo, 2004).

$\mathrm{Na}$ Declaração Final da II Conferência Nacional, os participantes afirmam o que querem, a saber:

... universalização do acesso da população brasileira que trabalha e vive no e do campo à Educação Básica de qualidade social por meio de uma política pública permanente; Ampliação do acesso e garantia de permanência da população do campo à Educação Superior por meio de uma política pública permanente; Valorização e formação específica de educadoras e educadores do campo por meio de uma política pública permanente; Formação de profissionais para o trabalho no campo por meio de uma política pública específica e permanente; Respeito à especificidade da Educação do Campo e à diversidade de seus sujeitos (Declaração Final da II Conferência de Educação do Campo, 2004).

Pode-se perceber que a II Conferência Nacional de Educação apontou novas demandas de reivindicações, dentre elas, além da Educação Básica, a necessidade de políticas públicas de educação superior destinada aos educadores e educadoras, bem como a formação de profissionais como agrônomos, técnicos em agropecuária, zootecnistas, profissionais ligados ao desenvolvimento sustentável e ao estudo da agroecologia familiar e camponesa. Percebe-se assim um avanço na II Conferência, que, além da necessidade de conquistar uma Educação Básica que respeite a diversidade e a identidade do universo camponês, também quer uma Educação Superior que possibilite que os trabalhadores rurais possam sair da condição de favelização rural dos Assentamentos de Reforma Agrária, devido ao modelo de Reforma Agrária proposto pelos governos FHC e Lula nos últimos 12 anos.

A educação do campo é vista como direito social e um dever do Estado, por parte das organizações promotoras e pelos movimentos sociais que aderiram à causa a partir da II Conferência. Neste sentido, os participantes da II Conferência afirmam o que vão fazer e apresentam 21 ações coletivas que contribuirão para efetivar as Políticas Públicas de Educação do Campo na plataforma do Estado Brasileiro.

Com a realização das duas Conferências promovidas pelos atores sociais do processo de luta pela terra e de luta por uma educação do campo, cresceu o interesse de universidades e centros de pesquisa em compreender o fenômeno social que veio, ao longo dos últimos 10 anos, ganhando força e consistência. Muitos grupos de pesquisa foram criados com o objetivo de entender o processo em construção, dentre eles, o eixo de interesse no Programa de Pós-Graduação em Educação da Universidade de Brasília UnB sobre Educação do Campo que se encontra ligado à Área de Concentração Educação e Ecologia Humana. 


\section{O PENSAMENTO DE GRAMSCI NA EDUCAÇÃO DO CAMPO}

Para compreender o pensamento de Gramsci na educação do campo torna-se necessário perguntar: como a teoria de Gramsci conseguiu penetrar nos movimentos sociais do campo? Assim, retornamos ao momento em que a CPT realizava as formações dos trabalhadores rurais por meio da organização popular, nas Assembléias, Encontros, Seminários e ações pedagógicas de ocupação das terras. Tudo é formação para o trabalhador do campo, que vai assimilando informalmente o que Gramsci já afirmava na primeira metade do século XX.

O contexto histórico era de abertura de setores da Igreja na América Latina, que faziam a chamada opção preferencial pelos pobres, conforme nos aponta Boff (1986) e Gutiérrez (1981). Os camponeses, em especial, viviam sua fé a partir de dois modelos antagônicos: a Igreja Conservadora descendente do Padroado e fiel à Hierarquia ${ }^{3}$ e a nova Igreja que nascia do povo com as experiências das CEBs, mais conhecida como Igreja PovoComunidade. Em 1968 é realizada a II Conferência dos Bispos da América Latina, em Medellín, que afirmou sua opção pelos pobres e em defesa da dignidade da pessoa humana, o que possibilitou o surgimento de estudos e pesquisas na Teologia a partir da realidade do povo excluído e marginalizado.

Surge a Teologia da Libertação na América Latina em 1970, tendo como expoentes Leonardo Boff, no Brasil, e Gustavo Gutiérrez, no Peru. E de onde surge a Teologia da Libertação? Com toda a certeza não é dos gabinetes e, muito menos, da academia. A Teologia da Libertação surge da exploração, do desmatamento, do empobrecimento e da miséria do homem, que se torna lixo na sociedade capitalista. Dentre as reflexões da Teologia da Libertação, acusada de ter mediações marxistas, se encontra a problemática da terra. Na década de 70 , segundo dados da CPT, $1 \%$ da população detinha $46 \%$ das terras no Brasil. Havia um profundo êxodo rural, comunidades inteiras eram expulsas de suas terras, ou seja, cerca de 24 milhōes de camponeses abandonaram o campo nas décadas de 70 e 80 para viver em situação de miserabilidade nas grandes cidades.

Com o surgimento da CPT em 1975, com o método de escuta da realidade, inicia um processo de educação não-formal com os trabalhadores do campo que resistiam e com aqueles que, na cidade, queriam retornar às suas origens. A educação proposta pela $\mathrm{CPT}$ era destinada à humanização, encarnada e histórica, o que possibilitava às pessoas lutar pela vida e se tornar sujeitos coletivos. O objetivo central é criar, no inconsciente dos trabalhadores do campo, a possibilidade real de construir uma sociedade mais justa e solidária. Para isso, evidentemente, sendo uma Pastoral da Igreja, associam tal construção como desejo de Deus.

E onde entra Gramsci em tudo isso? A resposta se encontra em quem ministrava a formação não-formal (não escolar) aos trabalhadores. Os agentes de pastoral ligados à CPT eram pessoas formadas, em sua maioria, em filosofia, teologia, sociologia, história e outros cursos de ciências humanas. Além disso, alguns intelectuais se comprometiam 
com a CPT e eram constantemente chamados para assessorar esses encontros e assembléias de formação para os trabalhadores do campo. Evidentemente, a CPT não iria chamar alguém que tivesse posição contrária ao pensado e refletido como sendo emancipatório aos trabalhadores. E a maioria desses formadores tinha uma concepção de mundo que se utilizava de duas matrizes, a saber: uma concepção teológica da libertação em Boff e Gutiérrez e, por outro lado, a mediação histórico-dialética de Gramsci, que sempre foi o referencial oculto das CEBs, da CPT e da Teologia da Libertação. Por isso mesmo, a idéia alicerçada no senso comum de que a Teologia da Libertação possui uma mediação marxista até certo ponto se confirma, mas uma mediação marxista a partir de Gramsci.

A educação e a escola, produtora de conformismo e adesão ao estabelecido, como afirmam muitos teóricos marxistas, entre eles Althusser (1983), têm a função de reproduzir as desigualdades sociais, a ideologia dominante e o sistema capitalista. Gramsci não nega que a escola possa ser um aparelho ideológico do Estado, mas acrescenta uma novidade: a de que a escola pode ser transformadora. Uma educação que possibilite a transformação da sociedade desumanizada em humanizada, de uma sociedade a-histórica em uma sociedade histórica, de uma educação desencarnada em uma educação encarnada. Essa era a mensagem da CPT, que assumia nesse discurso o pensamento de Gramsci. Neste sentido, não podemos negar a importância que tiveram os encontros, seminários e assembléias que puderam oportunizar a conscientização e, por meio das ocupações de terra, uma ação pedagógica de luta social.

Para Gramsci, existe na sociedade uma contradição entre dominados e dominantes. Os dominantes utilizam-se da dominação político-idelógica para alcançar a dominação econômica.

Para garantir a dominação econômica (exploração), existe uma dominação político-ideológica, cuja principal agência é o Estado, enquanto defensor dos interesses das classes dominantes. Essa dominação de classe político-ideológica se faz pela repressão - o exército, a polícia, as prisōes, a dominação pela força, que só deve ser acionada explicitamente em períodos de crise - e pela dominação ideológica - a produção de um consenso social que aceita a direção que a classe dominante dá à sociedade. (MOCHCOVITCH, 1988, p. 13).

Há, portanto, uma subordinação ideológica caracterizada pelo senso comum por parte da classe dominante, que consegue manter presa a classe dominada, inclusive os camponeses. $\mathrm{O}$ senso comum produzido, acriticamente, na sociedade burguesa traz em seu bojo relações que apresentam determinadas concepções de mundo a partir do conformismo sócio-político das massas que possuem a crença e a fé nas supostas verdades dogmáticas preparadas e objetivadas pela classe dominante e por convicçôes religiosas.

No entanto, o que a CPT fez na década de 70 e início da década de 80 foi organizar os trabalhadores para que, dentro do próprio corpo de trabalhadores, surgisse o que Gramsci chama de intelectuais orgânicos. A CPT, na década de 70 , entendia que era 
preciso organizar os trabalhadores e fazer surgir de seu interior os intelectuais orgânicos que dariam continuidade ao projeto de emancipação dos trabalhadores. É o que o MST e outros movimentos sociais do campo continuam realizando dentro de seus quadros, que sempre se renovam. Dessa mesma forma, surgiram dentro do movimento da educação do campo os intelectuais orgânicos, que, articulados com o movimento social do campo, começaram a relacionar teoria e prática acerca da educação do campo.

$\mathrm{O}$ intelectual tem por função homogeneizar a concepção do mundo da classe à qual está organicamente ligado, isto é, positivamente, de fazer corresponder esta concepção à função objetiva desta classe numa situação historicamente determinada ou, negativamente, de a tornar autônoma, expulsando desta concepção tudo o que lhe é estranho. O intelectual não é pois o reflexo da classe social: ele desempenha um papel positivo para tornar mais homogênea a concepção naturalmente heteróclita desta classe (PIOTTE, 1975, p. 19. In: MOCHCOVITCH, 1988, p. 18).

Os intelectuais orgânicos, como dirigentes e organizadores do movimento social, da organização, ao contrário do senso comum, trabalham pelo bom senso. Trata-se do intelectual orgânico da educação do campo, que irá produzir a disputa pela hegemonia por meio da construção das matrizes pedagógicas da educação do campo. Seu adversário, representante da classe dominante, é o próprio Estado, que não vê com bons olhos algo que surge das bases, e tenta cooptá-lo em seus discursos e em suas demandas. O Estado, na concepção de Gramsci, dá legitimidade para que uma classe mantenha a hegemonia sobre outra classe. Assim, na realidade camponesa, é o Estado que legitima a propriedade privada e sua expansão em latifúndios, determinando que os fazendeiros se tornem a classe dominante hegemônica em relação aos deserdados da terra, os camponeses. A classe hegemônica tem duas funçōes básicas, a de dominar o grupo social oposto e a de dirigi-lo moral e intelectualmente.

Segundo Gramsci (2001, p. 15):

Os intelectuais são um grupo autônomo e independente, ou cada grupo social tem uma sua própria categoria especializada de intelectuais. (...) Todo grupo social (...) o mundo da produção econômica, cria para si, ao mesmo tempo, organicamente, uma ou mais camadas de intelectuais que lhe dão homogeneidade e consciência da própria função, não apenas no campo econômico, mas também no social e político.

No entanto, há um aspecto interessante na concepção de Gramsci acerca dos camponeses, dado o momento histórico do século XIX e primeira metade do século XX, o qual se encontra transformado em nossos dias, já que podemos dizer com plena convicção que não somente as forças operárias, os sindicatos, os partidos políticos, mas os movimentos sociais do campo, entre eles o MST, produzem seus próprios intelectuais orgânicos, o que Gramsci (2001, p. 16) não admitia.

(...) a massa de camponeses, ainda que desenvolva uma função essencial no modo de produção, não elabora seus próprios intelectuais "orgânicos" e não "assimila" nenhuma camada de intelectuais "tradicionais", embora outros grupos sociais extraiam da massa dos camponeses muitos de seus intelectuais e grande parte dos intelectuais tradicionais são de origem camponesa. 
Por sua vez, Gramsci não se refere aos sem terras, aos excluídos da posse e do direito de viver na terra, mas aos grandes proprietários, latifundiários e fazendeiros pequenoburgueses. Caso fossem sem terras não teriam condições de ser intelectuais tradicionais de origem camponesa, pois lhes era negado o acesso à formação intelectual por meio da escola.

As cristalizaçóes ainda hoje resistentes nesses países são o clero e uma casta militar, duas categorias de intelectuais tradicionais fossilizadas na forma da metrópole européia. A base industrial é muito restrita e não desenvolveu superestruturas complexas: a maior parte dos intelectuais é de tipo rural e, já que domina o latifúndio, com extensas propriedades eclesiásticas, estes intelectuais são ligados ao clero e aos grandes proprietários (GRAMSCI, 2001, p. 18).

A escola, para Gramsci, tem um papel fundamental na legitimação da desigualdade social e na perpetuação da classe dominante como classe hegemônica. Diz Gramsci (2001, p. 19):

A escola é o instrumento para elaborar os intelectuais de diversos níveis. A complexidade da função intelectual nos vários Estados pode ser objetivamente medida pela quantidade de escolas especializadas e pela hierarquização: quanto mais extensa for a "área" escolar e quanto mais numerosos forem os "graus" "verticais" da escola, tão mais complexo será o mundo cultural, a civilização, de um determinado Estado.

\section{PEDAGOGIA ALTERNATIVA A PARTIR DOS CEFFAS: O CAMINHO CONTINUA}

$\mathrm{Na}$ terceira parte desta reflexão, pretende-se abordar uma das Pedagogias Alternativas de Educação do Campo, que desde o final da década de 60 consolidou-se no Brasil. Trata-se dos Centros Familiares de Formação por Alternância, que aglutinam duas organizaçōes, a Unefab ${ }^{4}$ e a Arcafar $^{5}$ (Sul e Norte), que utilizam a Pedagogia da Alternância como processo pedagógico no ensino-aprendizagem dos filhos e filhas de trabalhadores rurais no Brasil.

Entre seus objetivos, os CEFFAs:

(...) surgem como uma possibilidade de educação apropriada às necessidades sociais e históricas a fim de minimizar o êxodo, desenvolver o campo, superar as condições de pobreza, abandono, entre outras mazelas existentes no campo, através de uma formação conscientizadora dos jovens e suas famílias junto às comunidades. (NASCIMENTO, 2005, p. 23).

Também, na pesquisa realizada para compor a Dissertação de Mestrado, defino o conceito teórico que podemos dar aos CEFFAs, a saber:

O CEFFA é uma Associação de Famílias, Pessoas e Instituições, que buscam contribuir com o desenvolvimento sustentável, através da educação, num espírito de solidariedade, que busca facilitar os meios e os instrumentos de formação adequados ao crescimento dos educandos/as, sendo estes os principais protagonistas da promoção e do desenvolvimento integral (profissional, intelectual, humano, social, econômico, ecológico, espiritual) e de todo o processo de formação, valorizando a realidade local. (NASCIMENTO, 2005, p. 23). 
Os CEFFAs possuem sua origem nas Maisons Familiales Rurales da França, que desde a década de 30 do século XX desenvolvem uma alternativa de educação para os filhos e filhas de camponeses por meio da Pedagogia da Alternância. Seu surgimento se dá num período de crescimento da urbanização e a partir de processo de descaso dos governos com a educação destinada aos camponeses. Vendo tal necessidade, os camponeses de uma pequena região da França, em Sérignac-Péboudou, juntamente com o padre da cidade, Abbé Granereau, fizeram da casa paroquial uma escola primária para onde os alunos iam em períodos alternados.

A partir de 1935, a escola ganha força e os camponeses a batizam de Casa Familiar Rural, dando um sentido de que a escola é uma extensão da casa (pequena propriedade) de sua família.

Suas principais características são: estarem organizadas por meio de uma Associação de Pais e Alunos que tomam as decisóes da Casa ou da Escola, a Pedagogia da Alternância entre a família e a escola, o regime de internato durante o tempo em que o educando permanece na escola e um quadro de educadores que são chamados pelos CEFFAs de monitores.

Os instrumentos pedagógicos da Pedagogia da Alternância são: Plano de Estudo, Caderno da Realidade, Visita às Famílias, Folha de Observação, Serão, Viagens de Estudo, entre outros.

É simplista a idéia de que a Pedagogia da Alternância significa somente o período alternado entre escola e família. A Pedagogia da Alternância possui um corpo teórico de instrumentos pedagógicos que possibilita que o educando sinta que a alternância torna-se um processo de ensino-aprendizagem múltiplo, já que na família o jovem educando busca sistematizar e praticar aquilo que lhe foi ensinado. Esse fato fica claro nas palavras de Vanessa Braga, que foi aluna da Escola Família Agrícola de Goiás de 1997-2003, realizando o ensino fundamental e o ensino médio na EFA.

A Pedagogia da Alternância vem a ser um período de alternância onde o aluno/a fica 15 dias em casa e 15 dias na escola, mas não é só isso; esta pedagogia é muito mais ampla, vejo que ela é um sistema educativo muito interessante, pois com os instrumentos pedagógicos o aluno/a tem o objetivo de estudar a sua realidade; dentro disso é trabalhada a interdisciplinaridade, sendo assim ligada à formação integral do jovem. Esta pedagogia tem a contribuir para o meio rural no sentido de que o jovem está aprendendo a valorizar o seu meio; aprendendo novas tecnologias, favorecendo o meio sócio-econômico da região; na questão de valorizar a cultura camponesa de seus antepassados e ter a plena consciência de que seu meio é o melhor lugar para se viver, ter uma formação profissional adequada para desenvolver projetos que dão sustentabilidade para a sobrevivência da agricultura familiar (NASCIMENTO, 2005, p. 61).

Essa experiência se encontra presente em muitos países. Continentalmente, encontra-se assim dividida: na África, está presente em 16 países, com 150 CEFFAs; na Ásia, em dois países, com oito Centros; na América Latina, em 13 países, com 349 Centros; 
na América do Norte, presente no Canadá com um CEFFA. E, na Europa, encontra-se presente em 12 países, num total de 547 CEFFAs.

No Brasil, os CEFFAS surgiram a partir de 1969, no Estado do Espírito Santo, em especial, na cidade de Anchieta. A experiência foi trazida ao Brasil pelo Padre Humberto Pietogrande, jesuíta, que era missionário italiano no Brasil. Na Itália, as Casas Familiares da França se transformaram em Escolas Famílias Agrícolas sem alterar o modelo pedagógico.

Assim como na França em 1935 a Pedagogia da Alternância surge com um representante da Igreja, no Brasil, o Padre Humberto Pietogrande é o incentivador do surgimento da Escola Família Agrícola no Espírito Santo. Segundo Nosella (1977, p. 35) “a Igreja estava passando por uma transformação que se identificava com o movimento do Concílio Vaticano II, com a Encíclica Mater et Magistra do Papa João XXIII e com a Encíclica Populorum Progressio do Papa Paulo VI. Esse novo espírito induzia os padres a se preocuparem não somente com uma ação sacramentalizante como também com uma ação de promoção sócio-econômica do povo. Neste sentido, o jovem sacerdote - Padre Humberto Pietogrande, SJ - encontrou apoio, em seu propósito, nos outros sacerdotes da região (...) começou a movimentar amigos e instituições, a escrever e esboçar projetos enquanto esperava a hora de embarcar de novo para o Brasil" (NASCIMENTO, 2005, p. 46).

Atualmente, as EFAs, sem contar as Casas Familiares Rurais, estão presentes em mais de 200 CEFFAs espalhados de Norte a Sul, conforme se encontra demonstrado no quadro 1.

No Brasil, existem três modelos de CEFFAs que se utilizam da Pedagogia da Alternância e seus instrumentos pedagógicos, a saber: EFAs (Escolas Famílias Agrícolas), ligadas à Unefab, CFRs (Casas Familiares Rurais), ligadas à Arcafar Sul e Norte e, por fim, as ECRs (Escolas Comunitárias Rurais), que são independentes.

Quadro I: Centros Familiares de Formação por Alternância.

\begin{tabular}{|c|c|c|}
\hline \multicolumn{3}{|c|}{ CENTROS FAMILIARES DE FORMAÇÃO POR ALTERNÂNCIA - CEFFAs } \\
\hline EFAs & CFRs & ECRs \\
\hline $\begin{array}{l}\text { Enfatiza a formação escolar } \\
\text { dos educandos/as a partir do regi- } \\
\text { me seriado e regularizado junto } \\
\text { às Secretarias Estaduais de Educa- } \\
\text { ção (SEE), possuindo também a } \\
\text { formação técnica tanto no Ensino } \\
\text { Fundamental, bem como, de forma } \\
\text { mais específica, no Ensino Médio } \\
\text { onde se trabalha a Educação Profis- } \\
\text { sional de Técnico em Agropecuá- } \\
\text { ria. }\end{array}$ & $\begin{array}{l}\text { As CFRs têm como prioridade } \\
\text { a formação técnica do educando/a. } \\
\text { Diferenciam-se das EFAs por ado- } \\
\text { tar o regime de suplência. Existem } \\
\text { casos de o jovem permanecer duas } \\
\text { semanas na Escola e uma semana } \\
\text { na família.Por isso, em grande parte, } \\
\text { a denominação de Casa Familiar } \\
\text { Rural. }\end{array}$ & $\begin{array}{l}\text { Estão localizadas no Norte do } \\
\text { Espírito Santo-ES e também na } \\
\text { Bahia existem muitas experiências. } \\
\text { Possuem as mesmas característi- } \\
\text { cas metodológicas das EFAs; no } \\
\text { entanto, são grupos autônomos } \\
\text { que estão ligados a movimentos } \\
\text { sociais e eclesiais que pressionam } \\
\text { o poder local para realizar a implan- } \\
\text { tação e a aprovação da Pedagogia } \\
\text { da Alternância para que a experi- } \\
\text { ência possa ter validade. Por isso, } \\
\text { muitas experiências surgem com } \\
\text { o apoio das prefeituras locais, bem } \\
\text { como do Governo do Estado. }\end{array}$ \\
\hline
\end{tabular}

Fonte: NASCIMENTO, 2005, p. 51. 
Na concepção de Queiroz (1997, p. 61), a diferença entre EFAs e CFRs se dá a partir de que: ... a EFA acentua a escolaridade, a formação intelectual, apesar de existir a formação técnica. Isso se confirma na ausência do nome ESCOLA, no período de alternância (15 dias na escola, 15 dias na família), na opção pela segunda fase do primeiro grau em regime seriado durante quatro anos e na busca de regularização junto às Secretárias Estaduais de Educação. (...) A CFR acentua a formação técnica, a formação do agricultor. Por isso, não se chama Escola, mas CASA; o período de alternância é de duas semanas na família e uma semana na Casa; a opção é pela segunda fase do primeiro grau em regime de suplência.

Segundo Nosella (1977, p. 46), as EFAS surgem como movimento social educativo organizado pelos e para os próprios trabalhadores rurais e que continua a beneficiá-los.

As EFAs nasceram também no Brasil de uma convicção de que algo poderia ser feito para os agricultores e, em parte, pelos agricultores. Esta convicção, entrando em dialética com as condiçôes objetivas de seu contexto sócio-cultural e econômico, parece produzir uma situação ambígua. Será exatamente essa ambigüidade o ponto mais delicado da experiência a ser, analisado, porque, ao mesmo tempo em que não devemos desprezar certos resultados, também não podemos aderir acriticamente a uma iniciativa.

O mais importante disso tudo é que recentemente o CEFFA proporcionou a aprovação da Pedagogia da Alternância como modelo de educação para as escolas do campo. Trata-se do Parecer do CEB no 01/2006, do Conselho Nacional de Educação, aprovado em 01/02/2006 que recomenda a adoção da Pedagogia da Alternância em Escolas do Campo.

Os CEFFA cumprem as exigências legais quanto à duração do ano letivo, pois integram os períodos vivenciados no centro educativo (escola) e no meio sócioprofissional (família/comunidade), considerando como dias e horas letivos atividades desenvolvidas fora da sala de aula, mas executadas dentro do Plano de Estudo de cada aluno. Recomenda-se que o Projeto Político-Pedagógico de cada CEFFA adote as características da Pedagogia da Alternância na concepção de alternância formativa, isto é, alternância integrativa real ou copulativa, de forma a permitir a formação integral do educando, inclusive para prosseguimento de estudos, e contribuir positivamente para o desenvolvimento rural integrado e auto-sustentável, particularmente naquelas regióes/localidades em que prevalece a agricultura familiar. (Conselheiro Murilio de Avellar Hingel).

Afirma Paiva (1984, p. 19) a partir do texto de Mochcovitch (1988, p. 50):

O pensamento socialista e o movimento dos trabalhadores, por sua vez, irão se apropriar das propostas burguesas em sua versão radical, ou seja, da posição em favor da democratização do ensino e da cultura e contra a segmentação da escola, pela escola comum, única, capaz de ser oferecida a todos pelo Estado. Na verdade, entre as propostas liberais e as aspiraçôes proletárias de acesso ao saber e à escola se encenou em pequeno a luta maior: a derrubada da velha ordem e a contenção burguesa da revolução proletária.

Quanto ao aspecto dicotômico da escola para elites e da escola para a formação de trabalhadores que serão destinados à mão-de-obra da sociedade, Gramsci (2001, p. 33) nos alerta que: 
(...) a crise escolar que hoje se difunde liga-se precisamente ao fato de que este processo de diferenciação e particularização ocorre de modo caótico, sem princípios claros e precisos, sem um plano bem estudado e conscientemente estabelecido: a crise do programa e da organização escolar, isto é, da orientação geral de uma política de formação dos modernos quadros intelectuais, é em grande parte um aspecto e uma complexificação da crise orgânica mais ampla e geral. A divisão fundamental da escola em clássica e profissional era um esquema racional: a escola profissional destinava-se às classes dominantes e aos intelectuais, enquanto a clássica destinava-se às classes dominantes e aos intelectuais.

Para Gramsci, a educação é um instrumento de luta da sociedade civil, o campo positivo do Estado. No entanto, o curso mesmo tendo sido pensado e demandado pelos movimentos sociais e organizaçōes do campo foi encaminhado ao órgão competente, a saber: o Ministério do Desenvolvimento Agrário e o Ministério da Educação. Ambos os órgãos fazem parte da sociedade política, o que Gramsci consideraria o campo negativo do Estado. Logo, teremos alterações de foco, de interesses no projeto. Muitas vezes, interesses camuflados que não são percebidos pela sociedade civil, a demandatária do projeto.

Evidente que a intenção da sociedade civil é a de dispor um projeto alternativo de sociedade, mas será a mesma intenção da sociedade política ao autorizar o projeto alternativo? Entende-se aqui projeto alternativo o Curso de Especialização em Agricultura Familiar Camponesa e Educação do Campo, lembrando-se que desde o governo FHC vinha-se tentando implementar um canal de diálogo para a construção do referido curso. Somente no governo Lula é que houve maior sensibilidade para a execução do projeto. Mas por quê? Quais foram os motivos que levaram a sociedade política a autorizar um curso demandado pela sociedade civil? Quer dizer, então, que no governo de FHC não havia interesse em proporcionar aos demandatários a execução do projeto, enquanto no governo Lula houve esse interesse, quais os motivos? Comunhão com as posições da sociedade civil? Ou cooptação da sociedade civil, já que o projeto técnico não é elaborado pelos demandatários, mas pelos técnicos da sociedade política? É uma questão que realmente nos intriga. Talvez não tenhamos resposta, mas somente pelo fato de apresentarmos a dúvida, temos a convicção de que estamos contribuindo para a ampliação da curiosidade epistemológica na academia.

Afirma Coutinho (1985, p. 61) a partir do texto de Mochcovitch (1988, p. 32):

No âmbito da sociedade civil, as classes buscam exercer sua hegemonia, ou seja, buscam ganhar aliados para os seus projetos através da direção e do consenso. Por meio da sociedade política - que Gramsci também chama de Estado-coerção -, ao contrário, exerce-se sempre uma ditadura, ou, mais precisamente, uma dominação fundada na coerção.

Sabemos que a educação do campo, a básica e a superior, proveniente das discussões dos movimentos sociais do campo e de organizações que apóiam suas lutas e demandas caracteriza-se, em especial, por uma concepção de mundo contra-hegemônica. Há uma contra-hegemonia na educação do campo em relação à educação pensada ser a melhor para os filhos de assentados e trabalhadores rurais que se tornou senso comum e hegemônico 
na maioria dos municípios do Brasil, a saber: levar essas crianças para a escola da cidade em transportes precários e que demoram até mesmo 5 a 6 horas para se chegar à cidade. A educação do campo vem ser contrária a tal prática hegemônica, torna-se assim, contra-hegemônica ao apresentar novas alternativas, como os CEFFAs que aqui apresentei, as escolas de assentamentos do MST, as escolas itinerantes do MST próprias aos filhos de acampados (em plena luta pela terra), enfim, existem alternativas formuladas no interior dos próprios movimentos, próprias das classes dominadas.

No entanto, o que pensar quando a sociedade política coopta a idéia e a apresenta em forma de legislação? Se a educação é um dever do Estado, como afirma o próprio movimento de educação do campo, como pensar que a legalização das alternativas não sofra alterações por parte dos técnicos que estão fora do movimento? E, com isso, como superar os desafios que ainda impedem que os trabalhadores rurais tenham acesso a uma educação sem a visão dicotômica imposta pelas classes dominantes?

\section{CONSIDERAÇÕES FINAIS}

A reflexão proposta sobre o pensamento de Gramsci nas pedagogias alternativas de educação do campo não termina. Esse debate tende a se prolongar ainda mais no século XXI, principalmente, ao determinarmos que a sociedade política cumpra seu papel como protagonista de políticas educacionais que poderão ou não estar voltadas para atender aos desejos e anseios dos trabalhadores rurais; e, por outro lado, que a sociedade civil que apresenta em seu cotidiano de lutas sociais a realidade educacional que, a partir da educação do campo, transforma em luta constante por direitos de cidadania.

Nesse contexto, a educação do campo, com suas pedagogias alternativas, os CEFFAs, o MST, a CPT e os Sindicatos Rurais, entre outros, tem a missão de tornar a escola do campo uma produtora de saberes e romper com a reprodução da classe dominante, que tenta impor suas doutrinas e códigos e que justifica, em muitas ocasiōes, a divisão social do trabalho e a divisão social da educação.

Para Freitag (1980, p. 37) "Gramsci vai ser o autor que atribui à escola e a outras instituiçōes da sociedade civil (ou seja, aos AIE de Althusser) essa dupla função estratégica (ou seja, a função dialética) de conservar e minar as estruturas capitalistas”. Nessa direção, as estruturas capitalistas tentam, a todo custo, fazer o casamento entre o antigo latifúndio improdutivo e o Agronegócio e Hidronegócio, contrários ao desejo e anseio das milhares de famílias que lutaram ou ainda lutam pelo acesso à terra, à produção, ao cooperativismo e ao direito de ser gente.

Gramsci oferece à sociedade uma oportunidade de verificarmos que é possível construir uma contra-hegemonia em todos os setores do Estado, dentre eles, na escola. A história dos movimentos sociais comprova que é possível uma escola que se torne contrahegemônica ao modelo capitalista dominante. Para isso, é necessária uma nova práxis pedagógico-política que o MST, a educação do campo e outros movimentos sociais do 
campo e da cidade, como intelectual coletivo, e outras organizações estão desenvolvendo em suas ações coletivas.

Para concluir, D’Ávila (1985, p. 103) demonstra que a contra-hegemonia só pode ser vivida com a luta de classes que, ainda, apesar das discriminaçóes ao termo, constantemente se verifica na sociedade a partir dos conflitos, principalmente, no caso dos camponeses, entre sem terras e latifundiários, entre projeto de desenvolvimento popular e projeto de desenvolvimento capitalista, entre agronegócio e agricultura familiar camponesa, entre educação capitalista e educação do campo; enfim tais batalhas são vividas e continuarão a ser vivenciadas na história da humanidade:

... o processo de contra-hegemonia, no âmbito da luta-de-classes-na-pedagogia, tal como o desencadeamento da luta de classes, em seu sentido mais abrangente, passa necessariamente pela práxis, que é o momento em que se dá o encontro da teoria (esta já como resultado de uma reflexão sobre a prática histórica) com a prática política possível, dos agentes envolvidos com os interesses das classes dominantes.

\section{Notas}

1. Evidentemente, outros movimentos sociais do campo existem e possuem sua importância no cenário de lutas sociais implementadas pelos camponeses na busca dos direitos de cidadania que lhes foram negados por mais de 400 anos. Entre eles, destaco: os movimentos indígenas, as comunidades remanescentes de quilombos, os Sindicatos de Trabalhadores Rurais ligados a Contag, o Movimento dos Atingidos pelas Barragens e o Movimento dos Pequenos Agricultores. Além desses, Fernandes (2001, p. 66-67) aponta os vários movimentos sociais do campo dissidentes do MST ou também os chamados regionalistas, como é o caso do Movimento Camponês de Corumbiara - MCC de Rondônia.

2. Assinam a Declaração Final da II Conferência Nacional de Educação do Campo os seguintes Movimentos Sociais e Organizaçóes, a saber: CNBB, MST, Unicef, Unesco, UnB, Contag, Unefab, Undime, MPA, MAB, MMC, MDA/Incra/Pronera, MEC, Feab, CNTE, Sinasefe, Andes, Comissão de Educação e Cultura da Câmara dos Deputados, Frente Parlamentar das CEFFAs, Seap/PR, MTE, MMA, MinC, AGB, Consed, Fetraf, CPT, Cimi, MEB, PJR, Cáritas, Ceris, MOC, Resab, Serta, IRPAA, Caatinga, Arcafar Sul/Norte.

3. Mesmo estando em pleno Concílio Vaticano II, setores conservadores da Igreja no Brasil apoiaram a Ditadura Militar no Brasil em 1964. Mas, não obstante, surgem focos de resistência no interior da própria Igreja, em especial, os frades dominicanos que entram na resistência contra o Estado Militar conforme aponta, superficialmente, Germano (1993).

\section{Referências}

ALTHUSSER, Louis. Os aparelhos ideológicos do Estado. Rio de Janeiro: Graal, 1983.

BOFF, Leonardo. E a Igreja se fez povo. São Paulo: Círculo do Livro, 1986.

BRASIL. Lei de Diretrizes e Bases da Educação Nacional. Lei n. 9.394/1996. Brasília: MEC, 1996. 
CONFERÊNCIA. Declaração Final da I Conferência Nacional por uma Educação Básica do Campo. Luziânia, 1998 (mimeo).

Declaração Final da II Conferência Nacional Por uma Educação Básica do Campo. Luziânia, 2004 (mimeo).

COUTINHO, Carlos Nelson. $A$ dualidade de poderes: introdução à teoria marxista de estado e revolução. São Paulo: Brasiliense, 1985.

D’ÁVILA, José Luiz Piôtto. A crítica da escola capitalista. Petrópolis: Vozes, 1985.

FERNANDES, Bernardo Mançano. Questão agrária, pesquisa e MST. São Paulo: Cortez, 2001.

FREITAG, Bárbara. Quadro teórico. In: ______. Escola, estado e sociedade. 4. ed. São Paulo: Moraes, 1980. p. 15-43.

GERMANO, José Wellington. Estado militar e educação no Brasil (1964-1985). São Paulo: Cortez, 1993.

GOHN, Maria da Glória. Educação e movimentos sociais. 3. ed. São Paulo: Cortez, 1999.

GRAMSCI, Antonio. Cadernos do cárcere. Volume II. 2. ed. Rio de Janeiro: Civilização Brasileira, 2001.

GUTIÉRREZ, Gustavo. A força histórica dos pobres. Petrópolis: Vozes, 1981.

LEITE, Sérgio Celani. Escola rural: urbanização e políticas educacionais. São Paulo: Cortez, 1999.

MOCHCOVITCH, Luna Galano. Gramsci e a escola. São Paulo: Ática, 1988.

NASCIMENTO, Claudemiro Godoy do. Educação e Cultura: as escolas do campo em movimento. Fragmentos de Cultura, Goiânia: UCG-Ifiteg, v. 12, n. 3, p. 453-469, maio/jun. 2002.

. A educação camponesa como espaço de resistência e recriação da cultura: um estudo sobre as concepçōes e práticas educativas da Escola Família Agrícola de Goiás - Efago. 2005. 265f. Dissertação (mestrado), Faculdade de Educação, Unicamp, Campinas, SP.

NOSELLA, Paolo. Uma nova educação para o meio rural. 1977. 204f. Dissertação (mestrado), Faculdade de Educação, Pontifícia Universidade Católica, São Paulo, SP.

PAIVA, Vanilda Pereira. Perspectivas e dilemas da educação popular. Rio de Janeiro: Graal, 1984.

PIOTTE, Jean-Marc. O pensamento político de Gramsci. Porto: Afrontamento, 1975.

QUEIROZ, João Batista Pereira de. O processo de implantação da Escola Família Agrícola (EFA) de Goiás. 1997. 177f. Dissertação (mestrado), Faculdade de Educação, Universidade Federal de Goiás, Goiânia, GO.

SAVIANI, Dermerval. Educação e colonização: as idéias pedagógicas nos séculos XVI, XVII, XVIII. (mimeo), 1997. p. 1-12. . Escola e democracia. 34. ed. rev. Campinas: Autores Associados, 2001. 
The critical theory of Gramsci in alternative pedagogies of education in the rural areas Abstract

This article tries to reflect on the contribution of the thought of Gramsci in the elaboration and application of alternative pedagogies of education in rural areas, especially in the Training Centers in Alternation that work with the Pedagogy of Alternation in Brazil. The discussions on education in rural areas in Brazil are quite recent and for the last ten years have fortified themselves as a space for the construction of knowledge that is confirmed from the very experiences of collective subjects that construct alternative pedagogical spaces, in the Gramscian conception, counter-hegemonic to the established hegemony.

Keywords: Education in rural areas. Alternative pedagogies. Gramsci. Critical theory.

\section{La théorie critique de Gramsci dans les pédagogies alternatives de l'éducation en milieu rural} Résumé

Cet article cherche à réfléchir sur la contribution de la pensée de Gramsci dans l'élaboration et l'application des pédagogies alternatives de l'éducation en milieu rural, en particulier, celle des Centres de Formation en Alternance qui travaillent avec la Pédagogie de l'Alternance au Brésil. Les discussions sur l'éducation en milieu rural au Brésil sont bien récentes et il y a dix ans qu'elles se fortifient comme espace de construction du savoir qui se confirme à partir des expériences propres de sujets collectifs qui construisent des espaces pédagogiques alternatifs, dans la conception gramscienne, contre-hégémoniques à l'hégémonie établie.

Mots clefs : Éducation en milieu rural. Pédagogies alternatives. Gramsci. Théorie critique.

\section{La teoría crítica de Gramsci en las pedagogías alternativas de ecucación del campo. Resumen}

Este artículo busca reflexionar acerca de la contribución del pensamiento de Gramsci en la elaboración y aplicación de las pedagogias alternativas de educación del campo, en especial, la de los centros de formación en alternancia que trabajan con la pedagogía de la alternancia en Brasil. Las discusiones sobre educación del campo en Brasil son muy recientes y hace diez años son fortalecidas como espacio de construcción de conocimiento y de saberes que se confirman a partir de las propias experiencias de sujetos colectivos que construyen espacios pedagógicos alternativos, en la concepción gramsciana, contra hegemónico a la hegemonía establecida.

Palabras-clave: Educación del campo. Pedagogías alternativas. Gramsci. Teoría crítica.

Recebido: 06.09 .2007

Aceito: 17.03 .2008 